\title{
CALCULATION OF STRESS AND DEFORMATION IN FUEL ROD CLADDING DURING PELLET-CLADDING INTERACTION
}

\author{
DÁvid HALABUK*, JiŘí MARTINEC
}

\author{
Department of Power Engineering, Energy Institute, Faculty of Mechanical Engineering, Brno University of \\ Technology, Technická 2896/2, Brno 616 69, Czech Republic \\ * corresponding author: david.halabuk@gmail.com
}

\begin{abstract}
The elementary parts of every fuel assembly, and thus of the reactor core, are fuel rods. The main function of cladding is hermetic separation of nuclear fuel from coolant. The fuel rod works in very specific and difficult conditions, so there are high requirements on its reliability and safety. During irradiation of fuel rods, a state may occur when fuel pellet and cladding interact. This state is followed by changes of stress and deformations in the fuel cladding. The article is focused on stress and deformation analysis of fuel cladding, where two fuels are compared: a fresh one and a spent one, which is in contact with cladding. The calculations are done for 4 different shapes of fuel pellets. It is possible to evaluate which shape of fuel pellet is the most appropriate in consideration of stress and deformation forming in fuel cladding, axial dilatation of fuel, and radial temperature distribution in the fuel rod, based on the obtained results.
\end{abstract}

KEYWORDS: nuclear fuel; fuel rod; stress and deformation analysis; fuel cladding.

\section{INTRODUCTION}

Nuclear fuel used in pressurized water reactors is formed from uranium dioxide $\left(\mathrm{UO}_{2}\right)$. This ceramic fuel has the shape of small cylindrical pellets, and it is hermetically encased in long tubes made of zirconium alloy. Zirconium alloys have been selected for their good qualities such as geometric stability, small parasitic capture of neutrons, compatibility with $\mathrm{UO}_{2}$, corrosion resistance, good mechanical properties, etc. [1].

During irradiation, most of the nuclear fuel properties change. The mechanical and thermal properties change, as do the shape, structure and volume of the fuel pellet [1]. In a very early stage, the cracking of pellets occurs due to thermal stresses. Moreover, the ends of pellets expand more than their centre, and the pellet acquires an hourglass shape. Cracked fragments or deformed rim may cause a local force on cladding and thus concentrate a stress. There are also some specific phenomena that affect nuclear fuel properties, which are mostly direct consequences of the irradiation (swelling, densification, radiation growth, fission gas release, etc.) [2].

In certain cases, fuel pellets have modifications of their shapes which improve some of their properties. A typical example is a central hole, which reduces the peak temperature in the centre of the fuel and also increases the free volume of the fuel rod, where fission gas can be released. Another modification is related to the shape of the dished chamfered pellet, which reduces axial dilatation of the fuel column. Each of these changes of the pellet shape has an effect on the amount of stress and deformation in cladding during pellet-cladding interaction (PCI) [1].

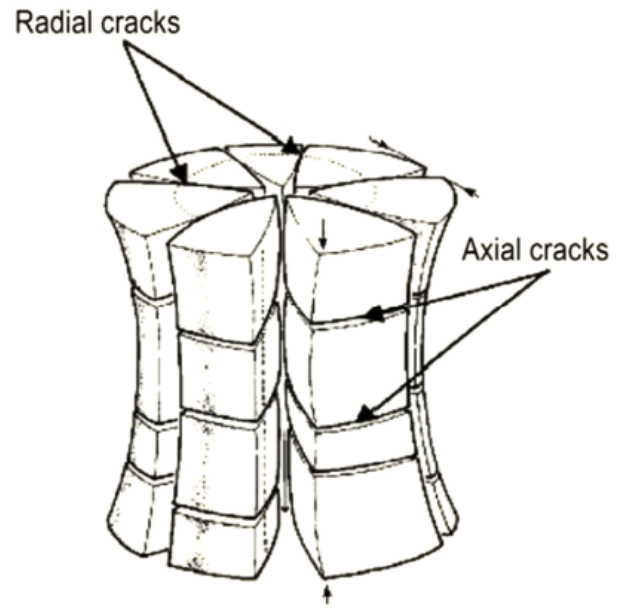

Figure 1. Pellet cracking due to thermal stress [2].

\section{Pellet-Cladding interaction}

The gap between the fuel and cladding is gradually reduced during operation (due to the thermal expansion and volume growth of the fuel pellet) and at high burnup the fuel can completely disappear. If contact between the pellet and cladding is created, stress and deformation of cladding are increased. This interaction may occur even earlier by the local power ramps (because of the different thermal expansion of the fuel and cladding) 3 .

Fission products, such as iodine and cesium, create an aggressive corrosion environment inside the fuel rods. If a small part of a cracked pellet is missing, fission products are accumulated in a free space between pallet and cladding. At that place on the inner surface of the cladding, a layer which is brittle and 


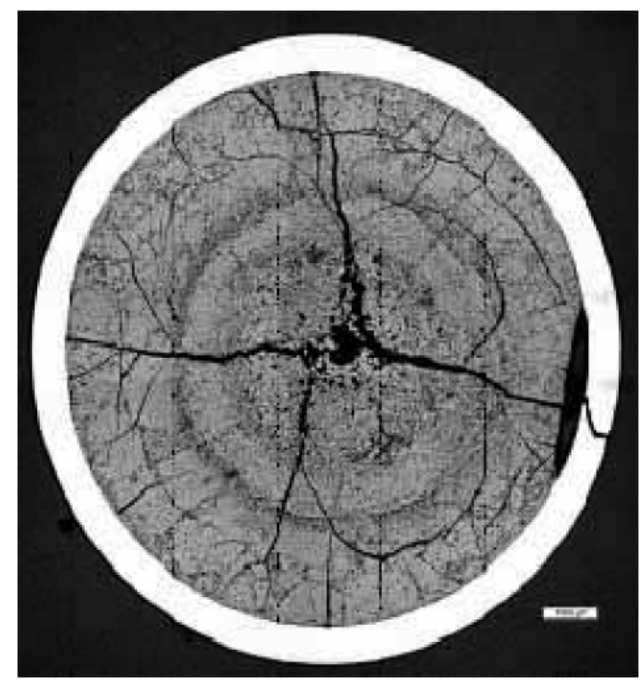

Figure 2. PCI failure due to SCC $\underline{3}$.

susceptible to cracking may form. If the cladding is in sufficient time exposed to a corrosive environment and to increased tension caused by the contact between the fuel and cladding, it may cause a stress-corrosion cracking (SCC) [3].

\section{STRESS AND DEFORMATION ANALYSIS}

The main goal of the analysis was to find the influence of the pellet shape on the deformation and stress which occurs in cladding during PCI. The axial dilatations of fuel columns and radial temperature distribution in fuel rods were also compared.

The calculation was done for two different states. The first state involved, a fresh fuel with a gap between the fuel and the cladding. The linear heat generation rate was $30 \mathrm{~kW} / \mathrm{m}$ and the pressure inside the fuel rod was $0.6 \mathrm{MPa}$. The second state was characterized by contact between the fuel and the cladding. Because it was a spent fuel, the linear heat generation rate was only $10 \mathrm{~kW} / \mathrm{m}$ and the pressure increased to $5 \mathrm{MPa}$ [4].

The diameter of the fuel pellets was $7.6 \mathrm{~mm}$ and their height was $12 \mathrm{~mm}$ [5]. Four various modifications of the basic pellet shape were compared in the analysis. The first two pellets had a cylindrical shape with and without a central hole, and the other two had a dished chamfered shape, also with and without a central hole. The central hole had a diameter $1.2 \mathrm{~mm}$ [5] and the geometry of the dished chamfered pellets is shown in Fig. 3 .

The geometrical model consisted of three fuel pellets, cladding and a spacer grid. Because of the 3 symmetry axes, the final model was only $1 / 6$ of the geometrical model. The outer diameter of the cladding was $9.1 \mathrm{~mm}$ and its thickness was $0.685 \mathrm{~mm}$ [1]. The spacer grid, with a thickness of $0.25 \mathrm{~mm}$ and a height of $10 \mathrm{~mm}$ [7], was placed on the interface of the $2 \mathrm{nd}$ and 3rd pellets.

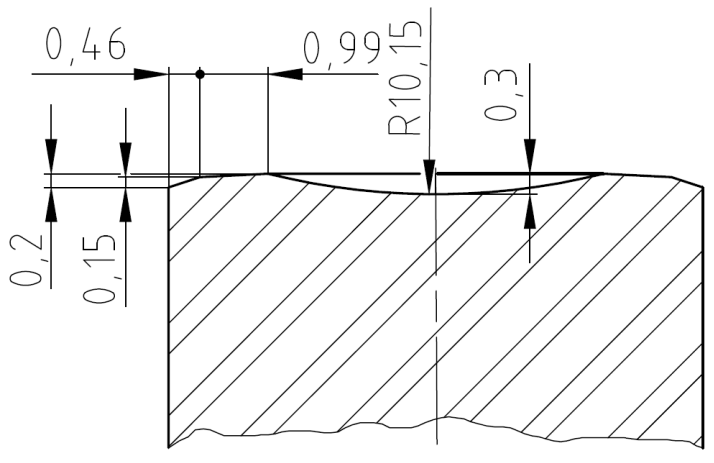

Figure 3. Dished chamfered face of fuel pellet 6 .

The external conditions correspond to the conditions in the VVER 440 reactor during normal operation (coolant temperature: $297^{\circ} \mathrm{C}$; pressure: $12.26 \mathrm{MPa}$ [4]).

$\mathrm{UO}_{2}$ was considered as the material of which the fuel pellets were made, the gap between the fuel and cladding was filled with pure helium, and the cladding and spacer grid were made of zirconium alloy. A $\mathrm{Zr} 1 \mathrm{Nb}$ alloy is used as cladding in the VVER 440 reactor, but in the absence of available information necessary for the calculation, a Zircaloy- 4 alloy was used for analysis. The thermal and mechanical properties of both alloys needed for the calculation (thermal conductivity, thermal expansion, modulus of elasticity, Poisson's ratio) are very similar in the used temperature range, and so the obtained results can also be used informatively for the Zr1Nb alloy. For more accurate results, an analysis using the material properties of $\mathrm{Zr} 1 \mathrm{Nb}$ alloy would be required. All properties of the materials were considered as dependent on the temperature, and the thermal conductivity of $\mathrm{UO}_{2}$ was in addition dependents on burnup [8].

The calculation for the elastic zone of material deformations was done by the FEM (Finite Element Method) programme ANSYS 14.5.

\section{Results}

Fig. 4 shows stress and deformation of cladding for state 2. Concentrations of stress and deformation occurred on the pellets interfaces, because of the nonuniform deformation of fuel pellets, hourglassing. The maximum value of stress was calculated on the inner surface, but the maximal deformations occurred on the outer surface of the cladding.

A comparison of the maximum values of stresses and deformations occurred in the cladding, for all various shapes of fuel pellets, is shown in Tab. 1. If the contact was not created, the cladding was loaded only by pressure and thermal load, which were not affected by the small changes of the pellet's shape. For this reason, deformation and stress for state 1 were essentially the same for all shapes. For state 2, the biggest deformation and stress occurred in the pellet without a central hole. The dished chamfered shape 


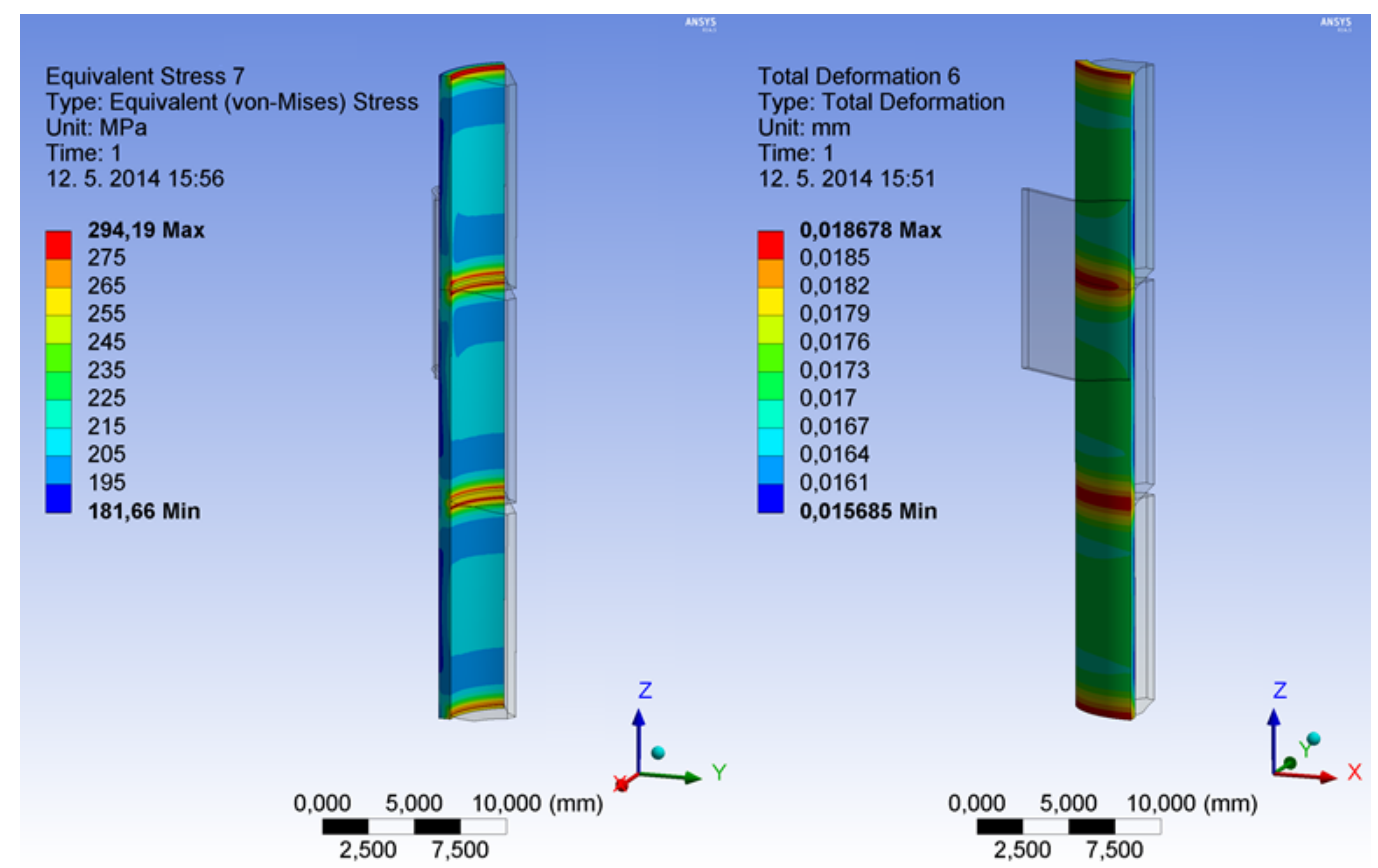

Figure 4. Stress (left) and deformation (right) of cladding for state with contact.

\begin{tabular}{llcccc}
\hline Cladding deformation & no contact [mm] & 0.0127 & 0.0127 & 0.0127 & 0.0127 \\
& contact [mm] & 0.0192 & 0.0186 & 0.0193 & 0.0187 \\
& difference [mm] & 0.0065 & 0.0059 & 0.0066 & 0.006 \\
& relative difference [\%] & 51.2 & 46.5 & 52.0 & 47.2 \\
\hline Stress in cladding & no contact [MPa] & 199.2 & 199.2 & 199.2 & 199.2 \\
& contact [MPa] & 312.2 & 301.2 & 303.3 & 294.2 \\
& difference [MPa] & 113.0 & 102.0 & 104.1 & 95.0 \\
& relative difference [\%] & 56.7 & 51.2 & 52.3 & 47.7 \\
\hline Axial dilatation & no contact [mm] & 0.473 & 0.434 & 0.392 & 0.38 \\
of 3 pellets & contact $[\mathrm{mm}]$ & 0.186 & 0.185 & 0.165 & 0.156 \\
\hline Temperature in centre & no contact $\left[{ }^{\circ} \mathrm{C}\right]$ & 1462 & 1371 & 1462 & 1371 \\
of pellet & contact $\left[{ }^{\circ} \mathrm{C}\right]$ & 646 & 616 & 646 & 616 \\
\hline
\end{tabular}

TABLE 1. Maximum value of deformation and stress in cladding, axial dilatation of fuel pellets, and temperature in centre of pellet.

had no influence on the deformation of the cladding, but when comparing the stresses, there was some effect. However, the dished chamfered shape had the biggest influence on axial dilatation of the fuel column. In the model, the difference of axial dilatations between the dished chamfered and the cylindrical shapes is only hundredths of millimetres, but at considering $2.5 \mathrm{~m}$ as the height of the fuel column, it already reaches a few millimetres. Predictably, the central hole had the biggest impact on the temperature in the centre of the pellets. There was a difference of $30^{\circ} \mathrm{C}$ between the pellets with and without a central hole for state 1 , and of $91{ }^{\circ} \mathrm{C}$ for state 2 .

According to the obtained results, the most appropriate shape in consideration of stress and deformation forming in fuel cladding, as well as of axial dilatation of fuel and radial temperature distribution in the fuel rods, is the dished chamfered shape with a central hole. The shape without dished chamfered faces and without the central hole is the most inappropriate one. However, it contains more mass and thus more fuel for fission reactions. This factor may be more influential, especially when the values of stress, deformation and temperature fall within a permissible range.

The results of the analysis show that stress was about $200 \mathrm{MPa}$ for state 1 , which is under ultimate strength. For state 2, there were higher values of stress only in a small region, but even there the strength limit was not exceeded, because the ultimate strength of zirconium alloy is increased after irradiation. A problem may occur only if other degradation effects (like grid to rod fretting, stress-corrosion cracking, hydriding, etc.) are added. In that case, the thickness of the cladding may be reduced or the surface may be defective, and together with increased tension it may induce a failure. 


\section{Conclusions}

The influence of the pellet shape on stress and deformation is not very strong for the selected model conditions. When the most appropriate and the inappropriate shapes are compared, the differences of the maximal values are less than $6 \%$. A larger differences, namely almost $24 \%$, is seen for the axial dilatations of the fuel column. The results of the calculations show that stress is under yield strength for each shape, even in full contact. A problem may occur only in combination with other degradation effects.

The main goals of development in nuclear research are to increase the safety, reliability and economic efficiency of nuclear fuel. Burnup, as well as fuel cycle length, is increased. This increase is possible due to higher fuel enrichment and more uranium mass in the reactor. In some reactors, there are already loaded pellets with extended diameter (from $7.6 \mathrm{~mm}$ to $7.8 \mathrm{~mm}$ ) and without a central hole [5]. When we keep the basic dimensions of fuel assemblies and fuel rods, the thickness of the cladding has to be decreased. These changes produce benefits such as higher efficiency of fuel utilization and decreasing amount of spent fuel. However, the thickness of cladding may be decreased only while still respecting the strength limits and the safety of nuclear fuel.

\section{REFERENCES}

[1] Bečvář, J.: Jaderné elektrárny. Praha: SNTL, 1978.

[2] Patterson C, Strasser A, et al.: Processes going on in nonfailed rod during normal operation. Skultuna, Sweden: Advanced Nuclear Technology International, 2010.

[3] International Atomic Energy Agency: Review of fuel failures in water cooled reactors. Vienna: IAEA, 2010.

[4] Heřmanský, B.: Termomechanika jaderných reaktorů. Praha: Academia, 1986.

[5] Ugryumov, A.: Nuclear fuel for npp: current status and main fields of the development. International Conference VVER 2013. Praha, 2013.

[6] Wolfgang, D., Hoff, A. et al.: Nuclear reactor green and sintered fuel pellets, corresponding fuel and fuel assembly. US20110176650. 2011.

[7] Rämä, T. et al.: Effect of spacer grid mixing vanes on coolant outlet temperature distribution. In: Kerntechnik. Vol. 77, No. 4, p. 265-270, 2012. DOI:10.3139/124.110252

[8] Siefken L.: SCDAP/RELAP5/MOD 3.3 code manual. MATPRO - A Library of Materials Properties for Light-Water-Reactor Accident Analysis. Washington, DC: Division of Systems Technology, Office of Nuclear Regulatory Research, U.S. Nuclear Regulatory Commission, 2001. 